\title{
Transvaginal ultrasound evaluation of ovarian volume among normal adults in Makurdi, North-Central Nigeria
}

\author{
Hameed Mohammad ${ }^{1 *}$, Stephen Dungbe Ngwan², Bernard Terkimbi Utoo ${ }^{3}$ and Terrumun Z Swende ${ }^{3}$ \\ *Correspondence: drhameed2001@yahoo.com \\ 'Department of Radiology, Benue State University Teaching Hospital, Makurdi, Nigeria. \\ ${ }^{2}$ Department of Obstetrics and Gynaecology, Federal Medical centre, Makurdi, Nigeria. \\ ${ }^{3}$ Department of Obstetrics and Gynaecology, Benue State University Teaching Hospital, Makurdi, Nigeria.
}

\begin{abstract}
Objective: This study was to evaluate the normal ovarian volume amongst normal adults using transvaginal ultrasound.

Methods: This was a hospital based prospective descriptive study carried out between May and December 2012 on consecutive patients presenting for ultrasonography at Federal Medical Centre Makurdi. Sonographic examination was done using Sonoscape SS1-1000 machine fitted with a 5.2 MHz transvaginal transducer and incorporated with an electronic calipers. With an empty bladder, the patient lay in a supine position and the transducer was advanced into the vagina. The ovarian volume of each patient was obtained. The sociodemographic data and body mass index of each patient was also recorded. The data was entered into an Excel sheet and analyzed using EPI INFO statistical software version 3.5.4.

$\underline{\text { Results: }}$ Two hundred and seven subjects were recorded for this study. The average volumes of the left and right ovaries were $6.5 \pm 3.3 \mathrm{ml}$ and $6.4 \pm 3.8 \mathrm{ml}$ respectively.
\end{abstract}

Conclusion: These values represent the normal average ovarian volume for healthy women in our environment.

Keywords: Transvaginal ultrasound, ovarian volume, correlates, transducer, body mass index

\section{Introduction}

Sonography is the imaging study of first choice in the investigation of cases of pelvic pathology. It is readily available, relatively inexpensive and uses a non-ionizing radiation. Though transabdominal approach is frequently done, the transvaginal technique is better. It gives a better resolution and hence improved visualization of the uterus and adnexa area. Moreover, the problem due to abdominal fat and the discomfort of full bladder are avoided. The technique is quick and gives accurate result in the assessment of ovarian size and volume.

The ovaries are paired ovoid structures. Each is located on either side of the uterus. They are found at the level of the fundus where the uterus becomes thinner. Though the exact positions are variable especially in the multi parous women, they usually lie adjacent to the psoas muscles with the iliac vessels lying laterally [1]. The ovarian size and volume are affected by diseases, drugs, ovulation and age $[2,3]$.

Evaluation of the ovarian size is accomplished with the formula for the volume of prolate ellipsoid (Volume=length $x$ height $x$ width $x$ 0.5233). In premenopausal women, the normal ovarian volume is documented to be between $5.3 \mathrm{ml}$ to $13.9 \mathrm{ml}$,

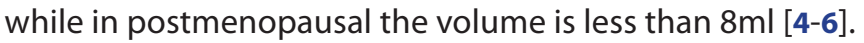

The clinical utility of measurement of ovarian volume include: screening for abnormalities of adolescences, diagnosis of Polycystic Ovarian Syndrome (PCOS), diagnosis and follow up of treatment of ovarian malignancies. Furthermore, ovarian volume measurement is important in the assessment of ovarian reserve and in predicting response to super ovulation.

It has been demonstrated that all ovaries assessed to be of normal morphology by ultrasound were found to be normal at the time of laparotomy and there was good correlation between ovarian volume as determined by ultrasound and by direct measurement at the time of laparotomy [7]. Likewise, Rodriguez, demonstrated that trans vaginal ultrasound had a sensitivity of $90 \%$ and a specificity of $100 \%$ when compared with the direct ovarian measurement at the time of surgery [8].

However, in the diagnosis of ovarian enlargement or abnormality, it is necessary to determine the normal range of ovarian volume in specific age groups. Studies on ovarian volume are generally lacking in Nigeria. A previous study on ovarian volume done in Enugu south eastern Nigeria used a transabdominal approach even though the transvaginal approach is more accurate [4]. A similar study done in Port Harcourt south south Nigeria using transvaginal approach however employed a smaller sample size [5].

The purpose of this study therefore is to assess the normal ovarian volume in healthy women in a defined Nigerian population through the transvaginal utrasonography.

\section{Methodology}

This was a prospective descriptive study. All consecutive clients who met the entry requirements were recruited between May 
Mohammad et al. Journal of Reproductive Biology and Health 2013,

Table 1. Distribution of age and parity of the women.

\begin{tabular}{lcc}
\hline Age group & Frequency (N207) & Percentage (100\%) \\
\hline$<20$ & 18 & 8.7 \\
$21-30$ & 101 & 48.8 \\
$31-40$ & 60 & 29.0 \\
$41-50$ & 14 & 6.8 \\
$>50$ & 14 & 6.8 \\
\hline Parity & & \\
\hline 0 & 80 & 38.6 \\
$1-2$ & 39 & 18.8 \\
$3-4$ & 48 & 23.2 \\
$>5$ & 40 & 19.2 \\
\hline
\end{tabular}

Table 2. Distribution of correlation of independent variables with ovarian volume.

\begin{tabular}{lccc}
\hline Variables & Ovarian volume & $\begin{array}{l}\text { Pearson } \\
\text { correlation }(\mathbf{r})\end{array}$ & $\begin{array}{l}\text { P-value } \\
\text { sig (2-tailed) }\end{array}$ \\
\hline Age & RT & -0.316 & 0.00 \\
\multirow{2}{*}{ Weight } & LT & -0.321 & 0.00 \\
& RT & 0.107 & 0.13 \\
Parity & LT & 0.142 & 0.04 \\
& RT & -0.070 & 0.32 \\
& LT & -0.015 & 0.83 \\
\hline
\end{tabular}

2011 and December 2012. Inclusion criteria included all non pregnant females whose age with clinically and sonographically healthy pelvic organs requesting an abdominopelvic scan. Clients on oral contraceptive pills, injectables or ovulation induction drugs were excluded from the study. So also were clients who had IUCD insitu or those who were unwilling to participate.

Sonographic examinations was done using a sonoscape machine fitted a 5.2MHz transvaginal sector transducer. With an empty bladder, the client lay in a supine position and the buttocks elevated with pillows. The transducer was advanced about 6 to $8 \mathrm{~cm}$ into the vagina angling laterally until the ovary was seen. The length and Antero-Posterior (AP) measurements were obtained in the longitudinal plane, while the transverse plane was used to measure the width. The age, height and weight of the clients were recorded. The menstrual phase and the parity were also recorded. The ovaries were classified into left and right. The data was entered into an Excel sheet and analyzed using EPI INFO statistical software version 3.5.4. The normal ovarian volume and the correlates were estimated for the population.

\section{Sample size}

For convenience the sample size for the study was 207 clients.

\section{Ethical considerations}

Ethical approval was obtained from the ethical committee of the Federal Medical Centre Makurdi. Informed written consent was obtained from the clients after the nature, aim and objectives of the study were explained to the clients in the language they best understood. Consenting participant signed a consent form or appended their thumb prints appropriately. The participants were given the option to opt out of the study if they so wished without affecting any benefit accruing to them.

\section{Results}

A total of 207 women were studied. The means of their social demographic features namely; age, parity, weight and height were, $31.2 \pm 10.5$ years, $2.5 \pm 4.1,63.0 \pm 11.3 \mathrm{~kg}$ and $1.87 \pm 0.4 \mathrm{~m}$ respectively. The average volumes of the left and right ovaries were $6.5 \pm 3.3 \mathrm{ml}$ and $6.4 \pm 3.8 \mathrm{ml}$ respectively.

Pearson's correlation analysis showed that ovarian volume was negatively correlated with age (RT ovary $r=-0.36, p<0.001$; LT ovary $r=-0.15, p=0.83$ ). Similarly, the ovarian volume was negatively correlated with parity (RT ovary $r=-0.070, p=0.32$; LT ovary $r=-0.015, p=0.83$ ). However, the ovarian volume was positively correlated with weight (RT ovary $r=0.107$; $L T$ ovary $r=0.142, p=0.04$ ). Analysis with one way ANOVA indicated a statistically significant difference amongst the menstrual phases and ovarian volume ( $R T$ ovary: $f=3.575, d f=5, p=0.04$; LT ovary: $\mathrm{f}=3.177, \mathrm{df}=5, \mathrm{p}=0.009$ ) (Tables 1 and 2).

\section{Discussion}

Transvaginal sonography which was described about two decades ago is more promising because it provides better resolution and hence more morphological details of the ovaries [9]. Our result showed the mean ovarian volumes for the left and the right ovaries were $6.5 \pm 3.3 \mathrm{ml}$ and $6.4 \pm 3.8 \mathrm{ml}$ respectively. These values are similar to that reported by other workers $[\mathbf{4 , 5}, \mathbf{1 0}]$. This also supports the assertion that there is no racial or geographical difference in values of ovarian volume. However, in a study of postmenopausal women Pongsatha S et al., showed that there is a racial difference between ovarian volume of Thai women and western women [11].

Ovarian volume gradually increases with age but becomes smaller at perimenopausal age of 40 years. This reduction in volume is said to be due to decrease in the number of follicles with advancing age [12]. This finding is demonstrated by our study where there is a significant negative correlation between ovarian volume and age $(P<0.001)$.

Similarly, our data has demonstrated a negative correlation between ovarian volume and parity. This could be due to the fact that with increasing parity, there is advancement in age which consequently led to a waning ovarian function. This finding supports the work by Goswamy et al., [13]. In contrast, Merz et al., reported that parity had no effect on ovarian volume [14].

Our study however, showed a positive correlation between ovarian volume and weight. This may be due to the fact that there is a general increase in the size of body organs with increasing weight and the ovaries are expected to increase in size and consequently volume. This relationship between 
ovarian volume and weight has been reported by other researchers [4,15].

Ovarian volume is expected to change with the different phases of menstrual cycle in keeping with the change in sizes of the follicles within them. This study showed a positive correlation between the ovarian volume and the phases of menstruation (RT ovary: $f=3.575, d f=5, p=0.04$; $L T$ ovary: $f=3.177$, $d f=5, p=0.009$ ). Joseph et al., in a work done in Enugu, South Eastern Nigeria also reported a similar finding [4]. However, this finding is in sharp contrast to that by Oppermann et al., who in a study done at Hospital de Clinicas de Porto algra, Brazil did not establish any statistical difference in ovarian volume in relation to the phases of menstruation [16].

\section{Conclusion}

Measurement of ovarian volume is important for accurate evaluation and management of ovarian disorders. The ultrasound which is readily available, simple and cost effective is better suited for our environment than other imaging modality. The values of ovarian volume from our study may provide a baseline of normal ovarian volume in our community.

\section{Competing interests}

The authors declare that they have no competing interests.

\section{Authors' contributions}

\begin{tabular}{|l|c|c|c|c|}
\hline Authors' contributions & MH & NS & BU & ST \\
\hline Research concept and design & $\sqrt{ }$ & $\sqrt{ }$ & $\sqrt{ }$ & $\sqrt{ }$ \\
\hline Collection and/or assembly of data & -- & $\sqrt{ }$ & $\sqrt{ }$ & -- \\
\hline Data analysis and interpretation & -- & $\sqrt{ }$ & -- & $\sqrt{ }$ \\
\hline Writing the article & $\sqrt{ }$ & -- & -- & $\sqrt{ }$ \\
\hline Critical revision of the article & -- & $\sqrt{ }$ & -- & $\sqrt{ }$ \\
\hline Final approval of article & $\sqrt{ }$ & $\sqrt{ }$ & $\sqrt{ }$ & $\sqrt{ }$ \\
\hline Statistical analysis & -- & -- & $\sqrt{ }$ & -- \\
\hline
\end{tabular}

Publication history

Editor: Giampiero Capobianco, University of Sassari, Italy.

EIC: Zeev Blumenfeld, RAMBAM Health Care Campus, Haifa, Israel. Received: 23-Aug-2013 Accepted: 26-Sep-2013

Published: 03-Oct-2013

\section{References}

1. Ryan $S$, McNicholas $M$ and Eustace $S$. The female reproductive tract. Anatomy for diagnostic imaging. $2^{\text {nd }}$ edition. Saunders. Edinburgh. 2007; 236-245. | Book

2. Pavlik EJ, DePriest PD, Gallion HH, Ueland FR, Reedy MB, Kryscio RJ and van Nagell JR, Jr. Ovarian volume related to age. Gynecol Oncol. 2000; 77:410-2. | Article | PubMed

3. Lass A, Skull J, McVeigh E, Margara R and Winston RM. Measurement of ovarian volume by transvaginal sonography before ovulation induction with human menopausal gonadotrophin for in-vitro fertilization can predict poor response. Hum Reprod. 1997; 12:294-7. | Article | PubMed

4. Joseph E, Ugwu AC and Christian N. Sonographic Quantification of Ovarian Volumes in an adult Nigeria population. Internet Journal of Medical Update. 2009; 4:15-8. I Pdf

5. Nwanko VC and Madufuro $\mathrm{CO}$. Transvaginal Ultrasound measurement of ovarian volume in PortHarcourt. J. Med. Med. Sci. 2011; 2:1080-1084. I Pdf
6. Higgins RV, van Nagell JR, Jr., Donaldson ES, Gallion HH, Pavlik EJ, Endicott $\mathrm{B}$ and Woods $\mathrm{CH}$. Transvaginal sonography as a screening method for ovarian cancer. Gynecol Oncol. 1989; 34:402-6. | Article | PubMed

7. Campbell S, Goessens L, Goswamy R and Whitehead M. Real-time ultrasonography for determination of ovarian morphology and volume. A possible early screening test for ovarian cancer? Lancet. 1982; 1:4256. | Article | PubMed

8. Rodriguez MH, Platt LD, Medearis AL, Lacarra M and Lobo RA. The use of transvaginal sonography for evaluation of postmenopausal ovarian size and morphology. Am J Obstet Gynecol. 1988; 159:810-4. | PubMed

9. Woo J. A short History of the development of Ultrasound in Obstetrics and Gynecology. Accessed on 18/8/13. I Website

10. Cohen HL, Tice HM and Mandel FS. Ovarian volumes measured by US: bigger than we think. Radiology. 1990; 177:189-92. | Article | PubMed

11. Pongsatha S, Tongsong T and Marakote N. Ovarian Volume Assessment by Transvaginal Ultrasonography in Postmenopausal Women. Thai Journal of Obstetrics and Gynaecology. 2002; 14:211-214. | Pdf

12. Faddy MJ, Gosden RG, Gougeon A, Richardson SJ and Nelson JF. Accelerated disappearance of ovarian follicles in mid-life: implications for forecasting menopause. Hum Reprod. 1992; 7:1342-6. | Article | PubMed

13. Goswamy RK, Campbell S, Royston JP, Bhan V, Battersby RH, Hall VJ, Whitehead $\mathrm{MI}$ and Collins WP. Ovarian size in postmenopausal women. Br J Obstet Gynaecol. 1988; 95:795-801. | Article | PubMed

14. Merz E, Miric-Tesanic D, Bahlmann F, Weber G and Wellek S. Sonographic size of uterus and ovaries in pre- and postmenopausal women. Ultrasound Obstet Gynecol. 1996; 7:38-42. | Article | PubMed

15. Eddy CS, Stephenie M and Rita F. A study to assess the Normal Values of Ovarian Volume For Women in Singapore using Transabdominal Ultrasound. The internet Research SGH procedings. 2004; 13:3.

16. Oppermann K, Fuchs SC and Spritzer PM. Ovarian Volume in pre and postmenopausal women a population based study. The internet $N C B I$ resource menopause. 2003; 10:309-313. I Website

Citation:

Mohammad H, Ngwan SD, Utoo BT and Swende TZ. Transvaginal ultrasound evaluation of ovarian volume among normal adults in Makurdi, North-Central Nigeria. J Reprod Biol Health. 2013; 1:1. http://dx.doi.org/10.7243/2054-0841-1-1 